\title{
EMILIE SNETHLAGE, UMA PESQUISADORA EXTRAORDINÁRIA EM UM UNIVERSO ACADÊMICO MASCULINO
}

\author{
Reinhard Michael Eugen Arnegger 1 \\ ${ }^{1}$ Universidade Federal do Pará, Belém, Pará, Brasil
}

Nelson Sanjad²

2Fundação Oswaldo Cruz/Museu Paraense Emílio Goeldi, Belém, Pará, Brasil

Foi traduzido do alemão um texto da pesquisadora Emilia Snethlage (1868-1929) com a seguinte referência bibliográfica: Snethlage, Emilia. «Zur Ethnographie der Chipaya und Curuahé». Zeitschrift für Ethnologie, 42, 1910: pp. 605-637.

A revisão final dessa tradução é de Nelson Sanjad, pesquisador do Museu Paraense Emílio Goeldi e grande conhecedor da etnologia alemã na Amazônia. Foi ele que incentivou a escolha desse texto importante de Emilia Snethlage, argumentando que o texto merecia muito uma tradução para o português, por ser a primeira etnografia sobre os Xipaya e Kuruaya, os quais nunca tiveram acesso a esse texto pelo fato de estar em alemão.

O título do artigo foi traduzido como "Sobre a Etnografia dos Xipaya e Kuruaya". Sendo o texto incluído integralmente na ata da sessão de 28 de maio de 1910 da Associação Berlinense de Antropologia, Etnologia e Pré-História, a qual era a editora da referida revista, abrangendo as páginas 605 a 637, foi decidido traduzir a referida ata por completo, guiado pelo seguinte motivo: a parte introdutória da ata, as páginas 605 a 608, onde constam as informações atualizadas para os filiados da Associação, dá uma breve impressão do contexto histórico da época. Porém, o motivo mais 
importante é a nota preliminar do renomado etnólogo alemão Theodor Koch-Grünberg (609-611), que apresenta o texto de Emilia Snethlage em um preâmbulo de três páginas.

Ao final do relato da pesquisadora, consta um glossário das línguas Xipaya e Kuruaya (627-637), elaborado pela mesma. Para poder concentrar-se na tradução, não foi incluído o glossário nesse trabalho, mesmo sendo essa lista de palavras de suma importância para as duas etnias. O glossário será objeto de um futuro estudo linguístico separado, com base nas transcrições fonéticas das denominações Xipaya e Kuruaya, escritas em sinais diacríticos.

Theodor Koch-Grünberg (1872-1924) já era, na época, uma autoridade acadêmica em sua área. O presente relato foi o primeiro texto etnológico publicado pela zoóloga e posterior Diretora do Museu Emílio Goeldi, Emilia Snethlage, "o qual marcou seu ingresso no círculo de antropólogos berlinenses, todos homens" (Sanjad, 07). A existência de pesquisadoras era vista, em geral, como uma ameaça. Poucas mulheres trabalhavam nessa época no âmbito acadêmico e em posições destacadas. Sem dúvida, Emilia Snethlage era uma pessoa insólita na etnologia e antropologia, tanto na Alemanha quanto no Brasil. Em 1914, tornou-se a diretora do Museu Goeldi, em Belém, sendo a primeira mulher a dirigir uma instituição científica na América do Sul.

Quanto à escolha de textos alemães sobre a Amazônia, diante do exposto, Emilia Snethlage foi a primeira opção de uma lista de exploradores, etnógrafos, botânicos e pesquisadores ilustres, tais como Karl F. P. Von Martius e Johann B. Von Spix, Barão de Langsdorff, Príncipe Adalbert da Prússia, Robert Avé-Lallemant, Karl Von den Steinen, Paul Ehrenreich, Princesa Therese da Baviera, Theodor Koch-Grünberg e Curt Nimuendajú, entre outros.

A tradução dos dois textos de Emilia Snethlage (1910 e 1921), apresentada nessa edição especial dos Cadernos de Tradução, dará um panorama mais completo da obra etnológica dela, porque as duas viagens são conectadas, com significativo ganho para os povos do Xingu. O texto de 1910 foi publicado depois da primeira viagem ao Xingu, feita em 1909 sob o patrocínio do Museu Goeldi. O texto 
de 1921 refere-se à segunda viagem ao Xingu, feita em 1914 sob o patrocínio do Museu Etnológico de Berlim (o texto só foi publicado em 1921 devido à I Guerra Mundial, em 1914-1918). Nessa segunda viagem, Emilia Snethlage formou uma coleção de objetos Xipaya e Kuruaya, que ela levou pessoalmente para Berlim em 1925.

Essa coleção está preservada até hoje e é a única existente no mundo sobre essas duas etnias. Portanto, os dois textos são de alta relevância e se complementam, sendo que o primeiro texto (1910) tem o atrativo de ter sido produzido após a famosa travessia entre o rio Xingu e o rio Tapajós, enquanto o segundo texto (1921) torna-se importante por ter sido produzido sob a influência de Karl Von den Steinen e de Eduard Seler. Emilia Snethlage chegou a viajar para Berlim em 1913 para negociar o apoio do Museu Etnológico com Karl Von den Steinen. Eduard Seler, etnólogo e membro de honra da Associação Berlinense de Antropologia, Etnologia e Pré-História, escreveu as instruções que ela deveria seguir para formar a coleção.

Mas, voltando para a tradução do relato da primeira expedição de Emilia Snethlage, de maio a outubro de 1909: optou-se por uma tradução moderadamente domesticada, no sentido de, por um lado, atualizar os nomes dos topônimos, das localidades geográficas e das etnias indígenas, por exemplo, Tapajós por Tapajoz, Jamanxim por Jamanchim, assim como Xipaya e Kuruaya por Chipaya e Curuahé, além de Juruna por Yurúna e Karajá por Caraja, sendo a atualização dos etnônimos de acordo com as regras da nomenclatura antropológica. Eles foram utilizados apenas no singular e com inicial maiúscula quando substantivos que designam povos indígenas; quando adjetivos, aparecem sempre no singular e com inicial minúscula.

Por outro lado, foram mantidas as denominações da pesquisadora quando se referiu aos indígenas, pois refletem uma perspectiva absolutamente comum à época, insistindo na diferença cultural dos brancos (identificados como "civilizados", "cristãos", "brasileiros") e dos indígenas, a quem chama Indianer ("índio", "índios”) e, em sua coletividade, Stamm ("tribo"), denominações, atualmente, com uma conotação marcada, para não dizer politicamente 
incorreta. A tradução menos polêmica seria hoje "indígena(s)" e "etnia" ou "povo". Porém, o texto perderia seu timbre ou teor histórico, se essas denominações fossem modernizadas na tradução.

Nesse contexto, entra certa postura da pesquisadora, que marca sutilmente as diferenças culturais entre ela e os indígenas ("meus Kuruaya", "número de cabeças" (613)), às vezes camuflando dependências mútuas durante uma viagem de meses ("Eu mesma tinha uma posição privilegiada, enquanto vivíamos da minha farinha." (614)). O texto é um relato que corresponde às expectativas da comunidade acadêmica e da instituição científica onde Emilia Snethlage trabalhava. Sua tarefa como pesquisadora, etnóloga e bióloga tinha como finalidade a descrição dos indígenas, suas estruturas sociais, suas habilidades, sua cultura e sua relação com a natureza, além da pesquisa de novos animais e plantas, para complementar as coleções naturais abrigadas nas instituições científicas e nos museus etnológicos e antropológicos na Europa e no Brasil.

A seguir, alguns breves comentários a respeito de particularidades na tradução do texto. Na página 609, Theodor Koch-Grünberg comenta que "a viajante voltou ao Pará". Pois, toda a viagem não aconteceu no Pará? Até o início do século XX, o nome "Pará" era usado com frequência para designar a cidade de Belém, além do estado ou da província que fica à leste da Amazônia brasileira.

Em relação à tradução de títulos profissionais e de titulações acadêmicas, buscou-se soluções aproximadas porque não existem denominações correspondentes na língua alvo. Foram os casos de "Geheimer Sanitätsrat" e "Privatdozent" na página 607, ou do título "Kreisphysikus" na página 608. Na mesma página, se mantem os títulos acadêmicos, que são de expressões latinas (studiosus medicinae; doctor philosophiae; studiosus rerum naturalium), em vez de traduzi-los. Nesse contexto, há de se mencionar o "falso amigo" "Professor" (pág. 607), que, em alemão, significa um alto título acadêmico, enquanto em português "professor" denomina a profissão de uma pessoa que ensina alunos.

Repetidamente, a pesquisadora coloca a denominação em português junto com a tradução alemã, uma das duas entre parêntesis, por 
exemplo em pág. 614, "mingau" (Suppe)"; "Kesseln (panellas)". Nesses casos foi traduzida a palavra alemã, o que resultou, às vezes, em uma dupla colocação. No caso da página 625, "Manoelsinho o chama de seu "padrão", manteve-se o original, marcado com [sic], porque se trata, evidentemente, de um erro ortográfico. Deve ser um erro ortográfico também "páo”, na pág. 626.

Entre as várias dificuldades de traduzir para a língua portuguesa, destaca-se, para finalizar, somente um caso: a diferença gramatical, como a língua original e a língua alvo expressam o discurso indireto. No alemão, o modo verbal subjuntivo, em concreto Konjunktiv I e Konjunktiv II, marca a fala de terceiro(s), tal como no inglês reported speech, enquanto que, em português, não se tem uma estrutura semelhante para tal função. Muitas vezes se recorre a verbos dicendi (dizem que; fala-se) ou preposições (segundo; conforme). Em nosso caso (610; segundo parágrafo) concreto, foi resolvido usar dois pontos após a fonte da informação, o pesquisador Henri Coudreau, no sentido "conforme Coudreau ....".

Especiais agradecimentos à professora visitante da UFPA, Katja Hölldampf, leitora do DAAD e coordenadora da Casa de Estudos Germânicos, que contribuiu com importantes sugestões para a elaboração da presente tradução, além de sua disponibilidade e paciência na hora da formatação dos textos. Outro parceiro importante foi Danrley Ribeiro, estudioso em Tecnologias da Informação, conseguindo com sua criatividade encontrar soluções para melhor adequação do texto. 


\section{Referência}

Sanjad, Nelson. "Nimuendajú, a Senhorita Doutora e os 'etnógrafos berlinenses': rede de conhecimento e espaços de circulação na configuração da etnologia alemã na Amazônia no início do século XX". Asclepio, 71(2), (2019): 273. https://doi. org/10.3989/asclepio.2019.14.

Reinhard Michael Eugen Arnegger. E-mail: arnegger@ufpa.br. https://orcid. org/0000-0003-0099-620X.

Nelson Sanjad. E-mail: nsanjad@museu-goeldi.br. https://orcid.org/0000-00026372-1185.

Cad. Trad., Florianópolis, v. 41, $\mathrm{n}^{0}$ esp. 1, p. 360-365, jan/jul, 2021.365 